\title{
Notiz über die Dissoziationswärme des Jods.
}

\author{
Von \\ JoACHIM SPERBER.
}

Auf Grund meiner Theorie von der Valenz ${ }^{1}$ habe ich die Dissoziations- und Verbindungswärmen verschiedener Elemente, darunter auch die des Jods, ${ }^{2}$ berechnet. Beim Jod mufste ich die Resultate als unentschieden hinstellen, ${ }^{3}$ weil mir bei demselben die für eine sichere Rechnung nötigen Daten fehlten. Während BoLTzMANN $^{4}$ die Dissoziationswärme des Jods zu 14.265 Kalorien berechnet hat, fand ich als solche 21 Kalorien.

In meiner jüngsten Publikation ${ }^{5}$ zeigte ich, „dafis das GAYLussac'sche Gesetz von der Ausdehnung der Amplituden der Atome bei der Dissoziation ebenso gut gelte, wie von der Ausdehnung der Gase". Es sei $A$ die Ausdehnung der Amplituden der Atome eines Elementes für die ganze Dissoziationswärme $w$, e für eine Kalorie, so ist nämlich:

Beim Jod ist

$$
e=\frac{A}{w}=\text { konstant }=0.0003046 .^{\circ}
$$

$$
A=0.004 .^{6}
$$

Setzt man diesen Wert für $A$ in die vorhergehende Gleichung ein, so erhält man:

$$
\begin{aligned}
0.0003046 & =\frac{0.004}{w}, \\
w & =\frac{0.004}{0.0003046},
\end{aligned}
$$

1 Das Parallelogramm der Kräfte als Grundlage des periodischen Systems in der Chemie (Zürich 1896, Verlag von E. Speides, Akad.-Polyt. Buchhandl.).

- Diese Zeitschr. 14, 164.

${ }^{2}$ Ebendaselbst S. 22.

${ }^{3}$ Ebendaselbst S. 23 und 26.

4 Sitrungsber. d. Alkad. d. Wissensch. (Wien 1884, II. Abth.) 88, 896.

${ }^{5}$ Diese Zeitschr. 14, 374.

'Das Parallelogramm der Kräfte etc., S. 22. 


$$
\begin{aligned}
\log w & =1.11833 \\
w & =13.132 \text { Kalorien }
\end{aligned}
$$

als Dissoziationswärme des Jods; eine Zahl, die der BoLtzmans'schen sehr nahe kommt.

Es gereicht mir zur besonderen Ehre, dals die nach meiner Theorie berechnete Zahl mit dem Resultate eines so ausgezeichneten Mathematikers und Forschers wie BoLtzmann übereinstimmt.

Ich hoffe, im Wintersemester die Experimente in Angriff nehmen zu können, die ich ausführen muls, um weitere Dissoziations-, Verbindungswärmon und Wärmetönungen auf Grund meiner Theorie berechnen zu können; ich werde dann auch das Jod in den Bereich meiner Untersuchungen ziehen, um dessen Dissoziations-, Verbindungswärme und Wärmetönung endgültig berechnen zu können.

Zürieh, im Juli 1897.

Bei der Redaktion eingegangen am 21. Juli 1897. 